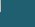

\title{
Effect of plasma glucose at admission on COVID-19 mortality: experience from a tertiary hospital
}

\author{
Bharat Kumar ${ }^{D}$, Madhukar Mittal, Maya Gopalakrishnan, Mahendra K Garg and Sanjeev Misra \\ All India Institute of Medical Sciences, Jodhpur, Rajasthan, India
}

Correspondence should be addressed to M Mittal: mittalspace@gmail.com

\begin{abstract}
Objective: Plasma glucose has been correlated with in-hospital mortality among many diseases including infections. We aimed to study the plasma glucose at the admission of hospitalized patients with COVID-19 at a tertiary care referral hospital at Jodhpur, India and its relation with mortality.

Design: A hospital-based clinical study of plasma glucose of COVID-19 patients conducted from May 15 to June 30, 2020 after ethical approval.

Measurements: Random blood samples at admission were collected for plasma glucose, interleukin-6 (IL6) and high sensitivity C-reactive protein (hSCRP) after written informed consent was obtained. Plasma glucose was analyzed by the automated analyzer, IL6 by chemiluminescent immunoassay and hsCRP by immune-turbidimetric assay.

Results: A total of 386 patients were studied (female 39.6\%); 11.1\% had severe disease and $4.1 \%$ expired. There were 67 (17.4\%) patients with known diabetes mellitus (DM). Patients with a history of DM had three times higher mortality $(6 / 67,9 \%)$ than those without DM (10/309, 3.1\%). Patients with moderate and severe disease according to ICMR and WHO grading had higher plasma glucose than those with asymptomatic or mild disease $(P<0.0001)$. Plasma glucose levels at admission were significantly higher in non-survivors when compared to those who survived $(297 \pm 117$ vs $131 \pm 73 ; P<0.0001)$. COVID-19 patients showed increased mortality with incremental plasma glucose levels. The hazard ratio for mortality was 1.128 (95\% Cl 0.86-14.860), 1.883 (95\% Cl $0.209-16.970)$, and 4.005 (95\% Cl 0.503-32.677) in random plasma glucose group of $>100-200,>200-300$ and $>300 \mathrm{mg} / \mathrm{dL}$, respectively, compared to those with random plasma glucose of $<100 \mathrm{mg} / \mathrm{dL}$ at admission. Plasma glucose was strongly correlated with hsCRP $(P<0.001)$ and IL6 $(P<0.0001)$.

Conclusions: Plasma glucose at admission in hospitalized COVID-19 patients is a strong predictor of mortality.
\end{abstract}

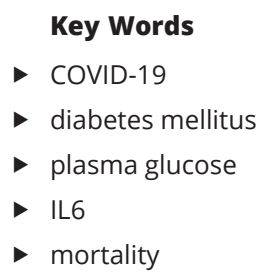

Key Words

- plasma glucose

\section{Introduction}

The novel coronavirus disease 2019 (COVID-19) originated from Wuhan, China, and then made its way to engulf the whole world, is caused by SARS-CoV-2 (severe acute respiratory syndrome coronavirus 2). It is a single-stranded RNA virus sharing $82 \%$ homology with human SARS-CoV, which causes severe acute respiratory syndrome (SARS) (1). COVID-19 infection has a mild presentation in the majority but can have unpredictable severe disease in a small percentage of patients who can go on to develop rapid-onset of devastating complications, including acute respiratory 
distress syndrome (ARDS), disseminated intravascular coagulation (DIC), cytokine storm leading to multiorgan involvement and shock. Certain characteristics can identify patients at high risk for developing severe COVID19 manifestations and mortality like advanced age, male sex, obesity, hyperglycemia, and presence of comorbidities (diabetes mellitus (DM), cardiovascular disease (CVD) and chronic kidney disease (CKD)) $(2,3,4)$.

Patients with DM are typically prone to severe SARS-CoV-2 infection (5), and poor glycemic control leads to increased hospitalization and mortality $(6,7)$. Hyperglycemia can increase viral proliferation as has been seen in human monocytes, where elevated glucose levels led to a direct increase in SARS-CoV-2 replication. Glycolysis maintains SARS-CoV-2 replication via the production of mitochondrial reactive oxygen species and activation of hypoxia-inducible factor-1 $\alpha$ (8). Besides, increased insulin resistance at peripheral and hepatic level, a combination of increased secretion of catabolic hormones (catecholamines, cortisol, and glucagon), increased hepatic gluconeogenesis, increased availability of lactate, use of carbohydrate-based feeds, glucosecontaining solutions, and drugs such as epinephrine, can all contribute to hyperglycemia $(9,10,11,12)$. In general, it is known that hyperglycemia can contribute to morbidity by creating a toxic cellular milieu, causing intracellular and extracellular dehydration, inducing electrolyte abnormalities, and depressing immune function $(13,14,15,16)$.

There are reports of association of plasma glucose at admission with morbidity and mortality with COVID-19 $(17,18,19,20,21,22)$. A guidance review suggests aggressive screening for hyperglycemia in patients with COVID-19 receiving systemic glucocorticoids (23). Infact, therapies including Tocilizumab have failed to decrease the elevated IL6 levels in hyperglycemic patients leading to a higher risk of severe outcomes than in normoglycemic patients (24). This study was conducted at a tertiary care hospital in Western India to evaluate the role of plasma glucose at admission and pre-existing (previously known) DM on mortality in patients of COVID-19.

\section{Material and methods}

This study was conducted at All India Institute of Medical Sciences, Jodhpur, Rajasthan, India from May 15 to June 30, 2020. Our center serves as the tertiary care referral hospital providing in-patient care to COVID-19 patients in Western Rajasthan. All patients were evaluated as per the
Indian Council of Medical Research (ICMR) guidelines and institutional protocol (Indian Council of Medical Research, New Delhi n.d. https://www.icmr.gov.in/ accessed January 13, 2021). The presence of SARS-CoV-2 was confirmed by reverse transcriptase PCR using standard testing protocols (Testing Strategy n.d. https://www.icmr.gov.in/cteststrat. html accessed January 13, 2021). All patients $>18$ years of age, admitted with COVID-19 were screened for inclusion. The study was approved by the Institutional Ethical Committee, AIIMS Jodhpur (AIIMS/RES/2020/4550).

Demographic profiles and comorbidities were collected using a standardized data collection proforma. All patients were categorized as asymptomatic, mild, moderate, or severe according to guidelines published by the Ministry of Health and Family Welfare (MoHFW), Government of India (mohfw n.d. https://www.mohfw.gov.in/ accessed January 13, 2021) and an additional category of critical as per World Health Organization (WHO) classification (Clinical management of COVID-19 n.d. https://www.who.int/publicationsdetail-redirect/clinical-management-of-covid-19 accessed January 13, 2021). All patients were treated with MoHFW guidelines. Patients with asymptomatic and mild categories were given symptomatic treatment. All patients with moderate and severe categories received antibiotics, remdesivir, low-molecular weight heparin, oxygen support by a nasal prong, mask, noninvasive ventilation, high flow nasal oxygen, or by invasive ventilation as decided by the treating physician.

The blood sample was collected during the admission in a sterile vacutainer and transported immediately for the measurement of plasma glucose, hsCRP and IL6. None of the patients had received dexamethasone for respiratory distress as per the existing protocols.

The plasma glucose was measured by an autoanalyzer. Normal range of random plasma glucose was considered as $<200 \mathrm{mg} / \mathrm{dL}$. Patients without previously known diabetes and random plasma glucose $\geq 200 \mathrm{mg} / \mathrm{dL}$ were labeled as 'new-onset hyperglycemia'. The interleukin-6 (IL6) assay was done by chemiluminescent immunoassay (Siemens Advia Centaur( immunoassay system, USA) and had analytical sensitivity of $2.7 \mathrm{pg} / \mathrm{mL}$, with a normal range of up to $4.4 \mathrm{pg} / \mathrm{mL}$. The highly sensitive C-reactive protein (hsCRP) was measured by immune-turbidimetric test using Beckman Coulter-AU system, USA. The normal range of hsCRP was $<1 \mathrm{mg} / \mathrm{L}$ and CV was $<5 \%$.

\section{Statistical analysis}

Data were analyzed using IBM SPSS Version 20.0. All categorical data were expressed as number (\%) and 
continuous data as mean \pm S.D. (95\% CI) and median (range). Plasma glucose was not normally distributed, hence, the analysis was performed by Mann-Whitney $U$-test. All categorical data were compared by the chisquare test. Cox proportional hazard ratio was used to assess the mortality risk among four categories of plasma glucose value (unadjusted and adjusted for age). Spearman correlation coefficient was used to find the correlation between plasma glucose and serum IL6 and hsCRP. A $P$ value of $<0.05$ was considered statistically significant.

\section{Results}

The demographic characteristics of patients are depicted in Table 1 . About $79 \%$ of patients were either asymptomatic or had mild disease. According to WHO classification, $7.8 \%$ had severe disease and $4.7 \%$ were critical, whereas according to MoHFW criteria $11.1 \%$ had severe disease. Most of the patients have recovered and discharged (95.9\%). There were 16 deaths (4.1\%). Mean duration of hospital stay was significantly longer among non-survivors when compared to survivors ( $14.9 \pm 7.4$ vs $9.4 \pm 3.5$ days; $P<0.0001$ ).

Age of non-survivors was significantly higher than in survivors $(63.4 \pm 14.0$ vs $48.1 \pm 16.3$ years; $P<0.0001)$; there was, however, no statistically significant difference in gender. Patients with diabetes, hypertension and acute kidney injury had a significantly higher mortality (Table 2). Interestingly, non-diabetics with random plasma glucose > 200 (new-onset hyperglycemia) on admission also had a greater fatality. Patients on oxygen or ventilators also had a higher risk of death. Expired patients had significantly lower lymphocyte and platelet count and increased total leukocyte and neutrophil count. Renal dysfunction and transaminase levels also differed significantly between survivors and non-survivors. Inflammatory markers (hsCRP, LDH, IL6, D-dimer) were significantly raised in non-survivors than in survivors.

\section{Plasma glucose}

The mean random plasma glucose of all patients was $138 \pm 82 \mathrm{mg} / \mathrm{dL}$. Patients with pre-existing (known) DM (67 patients-17.4\%) had significantly high plasma glucose when compared to those without known $\mathrm{DM}(217 \pm 120$ vs $121 \pm 80 \mathrm{mg} / \mathrm{dL} ; P<0.0001)$. Those patients admitted with random plasma glucose on $>180 \mathrm{mg} / \mathrm{dL}$ had significantly lower chance of survival when compared to those admitted with $\leq 180 \mathrm{mg} / \mathrm{dL}$
Table 1 Basic characteristics of COVID-19 patients.

\begin{tabular}{|c|c|c|}
\hline \multirow{2}{*}{$\begin{array}{l}\text { Parameter } \\
\text { Age (years) }\end{array}$} & \multicolumn{2}{|c|}{$n=386$} \\
\hline & & \\
\hline \multicolumn{3}{|l|}{ Gender } \\
\hline Male & \multicolumn{2}{|c|}{$233(60.4 \%)$} \\
\hline Female & \multicolumn{2}{|c|}{$153(39.6 \%)$} \\
\hline \multicolumn{3}{|l|}{ Comorbidities } \\
\hline Diabetes mellitus & \multicolumn{2}{|c|}{$67(17.4 \%)$} \\
\hline Hypertension & \multicolumn{2}{|c|}{86 (22.3\%) } \\
\hline Coronary artery disease & \multicolumn{2}{|c|}{$26(6.7 \%)$} \\
\hline COPD/Asthma & \multicolumn{2}{|c|}{$12(3.1 \%)$} \\
\hline Malignancy & \multicolumn{2}{|c|}{$3(0.8 \%)$} \\
\hline Severity & WHO criteria & MoHFW criteri \\
\hline Asymptomatic & $194(50.3 \%)$ & $194(50.3 \%)$ \\
\hline Mild & $110(28.5 \%)$ & $110(28.5 \%)$ \\
\hline Moderate & $39(10.1 \%)$ & $39(10.1 \%)$ \\
\hline Severe & $30(7.8 \%)$ & $43(11.1 \%)$ \\
\hline Critical & $13(3.4 \%)$ & - \\
\hline \multicolumn{3}{|l|}{ Outcome } \\
\hline Discharged & \multicolumn{2}{|c|}{$370(95.9 \%)$} \\
\hline Death & \multicolumn{2}{|c|}{$16(4.1 \%)$} \\
\hline Duration of stay (days) & \multicolumn{2}{|c|}{$9.8 \pm 4.2(3-42)$} \\
\hline Hemoglobin (gm/dL) & \multicolumn{2}{|c|}{$\begin{array}{c}13.1 \pm 2.0(12.9-13.3) \\
13.0(6.0-20.0)\end{array}$} \\
\hline $\begin{array}{l}\text { Total leucocyte count } \\
\text { (per } \mathrm{cm}^{3} \text { ) }\end{array}$ & \multicolumn{2}{|c|}{$\begin{array}{r}7636 \pm 8062(6805-8467) \\
6780(2000-150,440)\end{array}$} \\
\hline Neutrophil count (per $\mathrm{cm}^{3}$ ) & \multicolumn{2}{|c|}{$4750 \pm 4390(4298-5203)$} \\
\hline Lymphocyte count (per $\mathrm{cm}^{3}$ ) & \multicolumn{2}{|c|}{$\begin{array}{r}2366 \pm 7512(1593-3139) \\
1920(200-14,465)\end{array}$} \\
\hline $\begin{array}{l}\text { Platelet count (thousand } \\
\text { per } \mathrm{cm}^{3} \text { ) }\end{array}$ & \multicolumn{2}{|c|}{$250 \pm 927(246-259)$} \\
\hline Blood urea $(\mathrm{mg} / \mathrm{dL})$ & \multicolumn{2}{|c|}{$\begin{array}{c}24.0 \pm 14.7(22.8-25.6) \\
20.0(3-142)\end{array}$} \\
\hline Serum creatinine (mg/dL) & \multicolumn{2}{|c|}{$1.1 \pm 0.9(1.0-1.2)$} \\
\hline AST (U/L) & \multicolumn{2}{|c|}{$\begin{array}{r}33 \pm 30(30-36) \\
25(10-278)\end{array}$} \\
\hline $\operatorname{ALT}(U / L)$ & \multicolumn{2}{|c|}{$\begin{array}{c}35 \pm 53(29.9-40.7) \\
22.0(13-754)\end{array}$} \\
\hline Serum bilirubin (mg/dL) & & $1.0(0.0-2.0)$ \\
\hline $\mathrm{D}$-dimer $(\mu \mathrm{g} / \mathrm{mL})$ & \multicolumn{2}{|c|}{$\begin{aligned} 1.6 \pm & 4.3(1.1-2.0) \\
& 0.0(0.0-20.0)\end{aligned}$} \\
\hline $\begin{array}{l}\text { Random plasma Glucose } \\
\text { (mg/dL) }\end{array}$ & $\begin{array}{r}138 \pm 82( \\
105\end{array}$ & $\begin{array}{l}29-146) \\
6-585)\end{array}$ \\
\hline $\begin{array}{l}\text { Serum lactic } \\
\text { dehydrogenase (U/L) }\end{array}$ & $\begin{array}{r}245 \pm 105( \\
219\end{array}$ & $\begin{array}{l}34-255) \\
15-1016)\end{array}$ \\
\hline $\mathrm{hsCRP}(\mathrm{mg} / \mathrm{L})$ & $\begin{array}{r}25.2 \pm 51.2( \\
4.0\end{array}$ & $\begin{array}{l}9.9-30.4) \\
.04-371)\end{array}$ \\
\hline $\begin{array}{l}\text { Interleukin } 6(\mathrm{pg} / \mathrm{mL} \\
n=215)\end{array}$ & $\begin{array}{r}253 \pm 564( \\
28.0(\end{array}$ & $\begin{array}{l}57-309) \\
4-5500)\end{array}$ \\
\hline
\end{tabular}

Laboratory data are expressed as mean \pm s.D. $(95 \% \mathrm{Cl})$ and median (range). ALT, alanine aminotransferase; AST, aspartate aminotransferase; hsCRP, highly sensitive C-reactive protein; MoHFW, Ministry of Health and Family Welfare; WHO, World Health Organization.

(Fig. 1) (unadjusted hazard ratio $\mathrm{B}=-1.692$, hazard ratio $=0.184(95 \%$ CI $0.048-0.702), P=0.013$; hazard ratio adjusted for age $\mathrm{B}=-1.511$, hazard ratio $=0.221$ (95\% CI 0.057-0.850), $P=0.028$ ). Among patients with

is work is licensed under a Creative Commons Attribution-NonCommercial-NoDerivatives 4.0 International License ifica com at $04 / 26 / 202312: 08: 014 M$ 
Table 2 Predictors of mortality among COVID-19 patients.

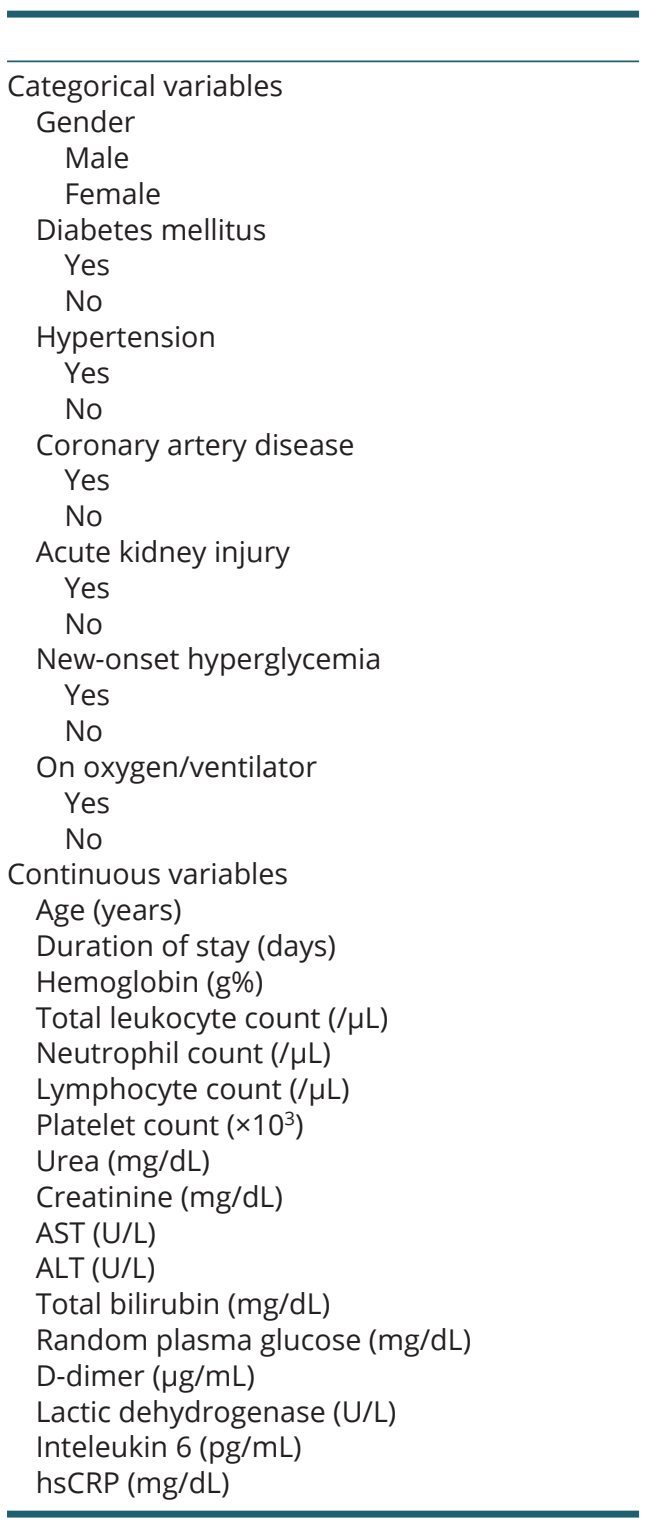

\begin{tabular}{c}
\hline Survivors $(n=370)$ \\
\hline $22(60.0 \%)$ \\
$148(40.0 \%)$ \\
$61(16.5 \%)$ \\
$309(83.5 \%)$ \\
$79(21.4 \%)$ \\
$291(78.6 \%)$ \\
$24(6.5 \%)$ \\
$346(93.5 \%)$ \\
$9(2.4 \%)$ \\
$361(97.6 \%)$ \\
$27(8.7 \%)$ \\
$282(91.3 \%)$ \\
$67(18.1 \%)$ \\
$303(81.9 \%)$ \\
$48.1 \pm 16.3$ \\
$9.6 \pm 3.8$ \\
$13.1 \pm 1.9$ \\
$7562 \pm 8192$ \\
$4611 \pm 4345$ \\
$2432 \pm 7671$ \\
$251 \pm 94$ \\
$22.8 \pm 10.5$ \\
$1.1 \pm 0.9$ \\
$32 \pm 28$ \\
$35 \pm 53$ \\
$0.51 \pm 0.53$ \\
$130.7 \pm 72.9$ \\
$237 \pm 3.9$ \\
$221 \pm 530$ \\
\\
\\
\\
\\
\\
\\
\\
\\
\\
\\
\\
\\
\end{tabular}

\begin{tabular}{c}
\hline Non-survivors $(n=16)$ \\
\\
$11(68.8 \%)$ \\
$5(31.2 \%)$ \\
$6(37.5 \%)$ \\
$10(62.5 \%)$ \\
$7(43.8 \%)$ \\
$9(56.2 \%)$ \\
$2(12.5 \%)$ \\
$14(87.5 \%)$ \\
$12(75.0 \%)$ \\
$4(25.0 \%)$ \\
$6(60 \%)$ \\
$4(40 \%)$ \\
$15(93.8 \%)$ \\
$1(6.2 \%)$ \\
$63.4 \pm 14.0$ \\
$15.8 \pm 7.6$ \\
$12.2 \pm 2.5$ \\
$9233 \pm 4162$ \\
$7790 \pm 4298$ \\
$930 \pm 532$ \\
$206 \pm 54$ \\
$52.7 \pm 42.1$ \\
$1.5 \pm 1.0$ \\
$64 \pm 41$ \\
$49 \pm 37$ \\
$0.75 \pm 0.45$ \\
$297.0 \pm 116.6$ \\
$5.7 \pm 7.2$ \\
$441 \pm 160$ \\
$110 \pm 66$ \\
\\
\end{tabular}

\begin{tabular}{c}
\hline P value \\
\hline \\
\\
0.336 \\
\\
\\
0.042 \\
\\
0.042 \\
\\
\\
\\
\\
\\
\\
\end{tabular}

ALT, alanine aminotransferase; AST, aspartate aminotransferase; hsCRP, highly sensitive C-reactive protein.

pre-existing DM, $41.8 \%$ (28 patients) had plasma glucose levels $>200 \mathrm{mg} / \mathrm{dL}$ on admission, whereas among those without known DM 10.3\% (33 patients) had plasma glucose $>200 \mathrm{mg} / \mathrm{dL}$. Random plasma glucose was significantly higher in patients with moderate and severe COVID-19 when compared to asymptomatic or mild COVID-19 (Fig. 2). Random plasma glucose values progressively increased from asymptomatic patients to patients with severe COVID-19 disease (asymptomatic $124 \pm 70$ (114-134), mild $105 \pm 29$ (100-111), moderate $169 \pm 85$ (141-196), and severe disease $255 \pm 110$ (221-289) $\mathrm{mg} / \mathrm{dL} ; P<0.0001$; by MoHFW criteria for severity).
Mean plasma glucose was significantly higher in non-survivors when compared to survivors (297 \pm 117 vs $131 \pm 73 \mathrm{mg} / \mathrm{dL} ; P<0.0001)$. Patients with pre-existing DM had three times higher mortality rate when compared with those without a history of pre-existing DM (9\% vs $3.1 \% ; P=0.042$ ). Mortality from COVID-19 showed increasing trend with rising random plasma glucose levels at admission (0.6, 2.0, 13.9 and $28.0 \%$ in patients with random plasma glucose of $<100,100-200,200-300$ and $>300 \mathrm{mg} / \mathrm{dL}$, respectively; $P=<0.0001)$. Unadjusted hazard ratio for mortality was 1.128 (95\% CI $0.086-14.860$ ), 1.883 (95\% CI 0.209-16.970), and 4.055 (0.508-32.677) in https://ec.bioscientifica.com https://doi.org/10.1530/EC-21-0086 (c) 2021 The authors Published by Bioscientifica Ltd
This work is licensed under a Creative Commons Attribution-NonCommercial-NoDerivatives 4.0 elnternationad dicense ifica. com at 04/26/2023 12:08:01AM 

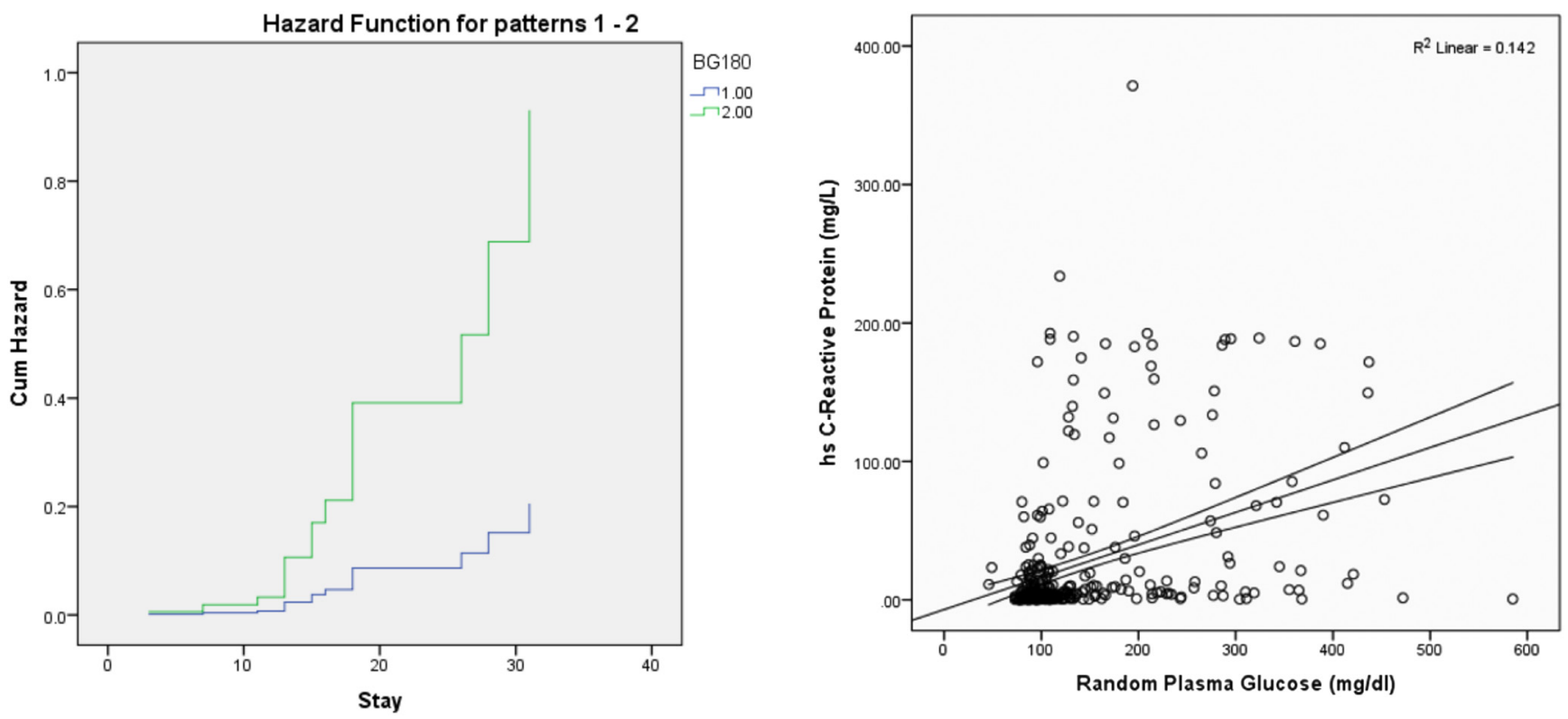

\section{Figure 1}

Cox proportional hazard ratio showing the relation of mortality with COVID-19 with random plasma glucose (group $1=\leq 180$; group $2=>180$ $\mathrm{mg} / \mathrm{dL}$; unadjusted hazard ratio $\mathrm{B}=-1.692$, hazard ratio $=0.184(95 \% \mathrm{Cl}$ $0.048-0.702), P=0.013$ )

random plasma glucose group of $>100-200,>200-300$ and $>300 \mathrm{mg} / \mathrm{dL}$, respectively compared to those with random plasma glucose of $<100 \mathrm{mg} / \mathrm{dL}$ on admission.

Random plasma glucose was also strongly correlated with inflammatory markers (hsCRP $P<0.001$, Fig. 3 ) and IL6 $P<0.0001)$.

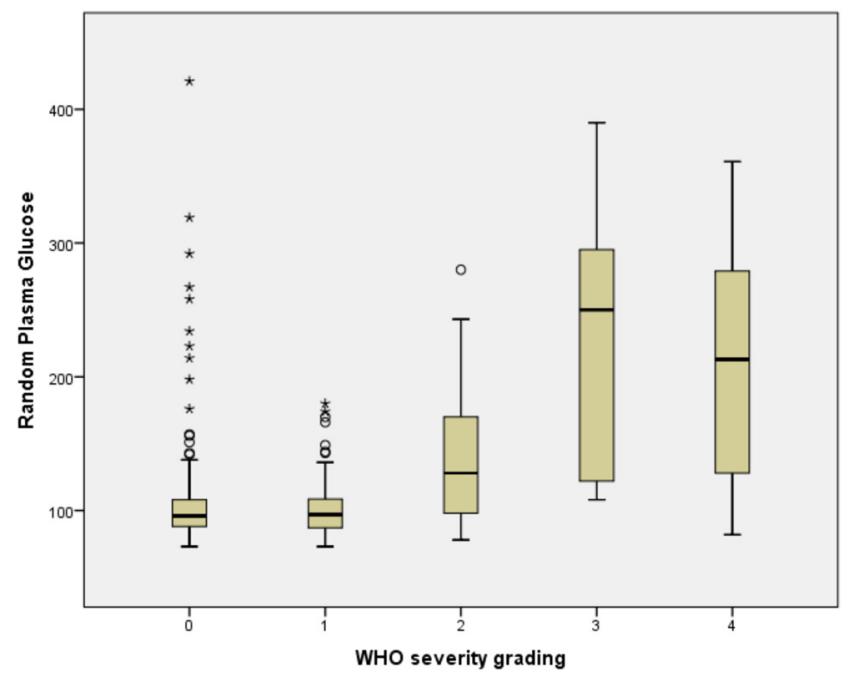

Figure 2

Box plot of the plasma glucose according to WHO staging: $0=$ asymptomatic, $1=$ mild, $2=$ moderate, $3=$ severe, $4=$ critical .

\section{Figure 3}

Scatter plot showing the correlation of random plasma glucose with hs-CRP. Lines indicate mean and $95 \% \mathrm{Cl}$.

\section{Discussion}

In this study, we found that patients with pre-existing (known) DM had a three-times higher mortality rate as compared to those patients without previously known DM. Higher plasma glucose levels on admission were predictive of moderate to severe disease according to ICMR and WHO grading, were associated with a higher mortality and were strongly correlated with markers of inflammation (including hs-CRP and IL6). There was an increase in hazard ratio for mortality with every $100 \mathrm{mg} / \mathrm{dL}$ increase in plasma glucose level. Patients admitted with plasma glucose $\leq 180 \mathrm{mg} / \mathrm{dL}$ had better survival than those with higher plasma glucose levels.

\section{Pre-existing (known) diabetes}

In our overall cohort, $17.4 \%$ patients had pre-existing DM. The percentage of patients with DM in COVID-19 cohorts has varied from 11 to $42 \%$ in different series $(5,6,7,8,25)$. In a retrospective cohort of 584 COVID-19 patients from Wuhan, the number of patients with pre-existing DM was $84(14.38 \%)$ (19). In a study from Delhi, the numbers of patients with pre-existing DM were higher at 189 (47.1\%) (25). In another study from Italy, out of 413 subjects, 107 (25.6\%) had diabetes, including 21 who were newly diagnosed (8). In a larger data-set of 1122 patients with COVID-19 from 88 US hospitals distributed across 10 states, 194 patients (17.3\%) with diabetes (defined as having an

This work is licensed under a Creative Commons Attribution-NonCommercial-NoDerivatives 4.0 elfternationab ficense.ifica . com at $04 / 26 / 2023 \quad 12: 08: 01 \mathrm{AM}$ 
A1C value $\geq 6.5 \%$ ) were identified. An additional 257 patients with uncontrolled hyperglycemia (two or more BGs $>180 \mathrm{mg} / \mathrm{dL}$ occurred within any 24-h period) were seen (26). In our series, among patients with pre-existing DM, $41.8 \%$ (28 patients) had plasma glucose levels $>200$ $\mathrm{mg} / \mathrm{dL}$ on admission.

\section{New-onset hyperglycemia}

Around $10.3 \%$ patients without pre-existing diabetes had a random plasma glucose $>200 \mathrm{mg} / \mathrm{dL}$ on admission labeled as 'new-onset hyperglycemia'. Impaired glucose regulation is typically seen in COVID-19 patients leading to new-onset hyperglycemia, worsening control in DM, severe insulin resistance requiring high insulin dosages and even diabetic ketoacidosis (DKA) $(27,28,29,30)$, and these are associated with increased levels of inflammatory cytokines (31). These changes can affect the functions of the skeletal muscle and liver, the organs responsible for the bulk insulin-mediated glucose uptake (32). The majority of DKA cases worldwide occur in patients with T2DM due to its higher prevalence, although ketoacidosis is typically associated with T1DM (33). A similar pattern has been observed in patients with COVID-19 in a systematic review, where $77 \%$ of patients with COVID-19 who developed ketoacidosis had T2DM (28). Interleukin-6 has also been found to be elevated in DKA and serves as a driver of ketogenesis (34), although no case of DKA was seen in our cohort despite elevated IL6 levels. It has been seen that uncontrolled hyperglycemia with or without pre-existing diabetes in COVID-19 has been associated with a higher mortality (35).

\section{Mortality}

A higher plasma glucose was associated with higher mortality. Patients with a history of DM had three times higher mortality rates (9\%) than those without DM (3.1\%). A similar pattern was observed from Wuhan where death ( $20.2 \%$ vs $8.0 \%, P=0.001)$ in the diabetes group was significantly higher than that in the non-diabetes group (6). In the Pisa study, mortality was greater in hyperglycemia group (39.4\% vs $16.8 \%$; unadjusted hazard ratio (HR) $2.20,95 \%$ CI $1.27-3.81, P<0.005)$ than in normoglycemia group (16.8\%) and marginally so in diabetes group (28.6\%; $1.73,0.92-3.25, P<0.086)$ patients $(7)$. In the multicenter study from the US, the mortality rate was $28.8 \%$ in 184 diabetes and/or uncontrolled hyperglycemia patients compared with $6.2 \%$ of 386 patients without diabetes or hyperglycemia $(P<0.001)(26)$.
Previously known diabetic status and new-onset hyperglycemia both had a higher mortality rate in our study. Other predictors of mortality were renal dysfunction and oxygen requirement including invasive ventilation. Non-survivors were older, had a longer duration of hospital stay and significantly increased levels of IL6, hsCRP, LDH and D-dimer. In the study on 133 COVID-19 patients by Mazori et al., those with new-onset hyperglycemia having blood glucose $>180 \mathrm{mg} / \mathrm{dL}$ during the first 2 days after ICU admission had higher levels of median C-reactive protein (306.3 $\mathrm{mg} / \mathrm{L}, \quad P=0.036)$, procalcitonin $(1.26 \mathrm{ng} / \mathrm{mL}$, $P=0.028)$, and lactate $(2.2 \mathrm{mmol} / \mathrm{L}, P=0.023)$ (21). Procalcitonin and lactate levels were not measured in our study. In a study from the Huoshenshan hospital in Wuhan, which tracked the progression of COVID-19 patients from admission to discharge/death, age above 60 years, elevated levels of blood glucose, C-reactive protein, lactate dehydrogenase, direct bilirubin, low albumin and lymphocyte count were significant risk factors for progression. Around $17 \%$ of the 2433 patients received systemic glucocorticoids in their patient cohort and the total mortality rate was $2.1 \%$ (22). Lower lymphocyte counts and lymphopenia were seen in non-survivors in our study as well.

The mortality data in our series have been much lower than that reported from various Western countries. The overall lower mortality seen in India and South Asia has flummoxed the world medical community and various reasons have been proposed for it $(36,37)$. As of January 02, 2021, on the World Health Organization COVID-19 dashboard, 82,579,768 confirmed cases of COVID-19 have been reported including $1,818,849$ deaths. During the same period, cases from India have been 10,305,788 with 149,218 deaths (WHO Coronavirus Disease (COVID-19) Dashboard n.d. https://covid19.who.int accessed January $3,2021)$. The fatality rate from Western data for COVID19 has been estimated to be $0.5-1.0 \%(38,39,40)$. As per the World Health Organization (WHO) situation report on January 5, 2021, India has one of the lowest cumulative deaths per 1 million population (India 108, Europe 631, USA 1043). The various factors responsible for the low mortality rates seen in India need further elucidation.

\section{Disease severity}

Patients with moderate and severe disease according to ICMR and WHO grading had a higher plasma glucose than those with asymptomatic or mild disease $(P<0.0001)$. In the study from Delhi, patients with diabetes had a higher proportion of severe cases $(20.1 \%$ vs $9 \%$, 
$P=0.002)$, ICU admission (24.3\% vs $12.3 \%, P=0.002)$, and oxygen requirement (53.4\% vs $28.3 \%, P<0.001)(25)$. Baseline HbA1c correlated significantly with outcome severity scores $(\mathrm{r}=0.136, P=0.013)$ although this was not available for our cohort. In another series from China, $32 \%$ of COVID-19 severe cases were patients with diabetes while only $10.9 \%$ of mild cases had diabetes $(P<0.05)$ (41). Hyperglycemia on day-1 has been shown to be the best predictor of radiographic imaging of SARS-CoV2, regardless of the past medical history of diabetes (42). In a study from Cleveland, mechanical ventilation rates were significantly higher in the hyperglycemic group at $50.0 \%$ vs $37.2 \%(P=0.004)(43)$. Increased risk for hyperglycemia was found in patients with steroid use (odds ratio (OR) 1.521; 95\% CI 1.054, 2.194) along with triglycerides $\geq 150 \mathrm{mg} / \mathrm{dL}$ (OR 1.62; 95\% CI 1.109, 2.379), and African-American race (OR 0.79; 95\% CI 0.65, 0.95). In our study, steroids were not used as per the ICMR protocol prevalent during that time.

\section{Inflammatory markers}

Positive correlation was seen between plasma glucose and markers of inflammation including hsCRP $(\mathrm{r}=0.377$, $P<0.0001)$ and IL6 $(\mathrm{r}=0.292, P<0.0001)$ in our study (Fig. $3)$. In a study by Cheng et al, the COVID-19 patients with T2DM group had higher erythrocyte sedimentation rate (ESR) and levels of C-reactive protein, IL6, tumor necrosis factor-alpha, and procalcitonin but lower lymphocyte counts and $\mathrm{T}$ lymphocyte subsets compared with the nondiabetic group (44). Similar pattern of a higher prevalence of known diabetes in ICU than non-ICU patients (31.7\% vs $17.8 \%, P=0.0408)$ was seen in another study. Multivariable regression analysis showed that a history of diabetes (odds ratio (OR), 0.099; 95\% CI, 0.016-0.627; $P=0.014$ ), high FPG at admission (OR, 1.587; 95\% CI, 1.299-1.939, $P<0.001$ ), high IL6 (OR, 1.01; 95\% CI, 1.002-1.018, $P=0.013)$, and D-dimer higher than $1 \mathrm{mg} / \mathrm{L}$ on admission (OR, 4.341; 95\% CI, 1.139-16.547, $P=0.032$ ) were independent predictors of poor outcomes (45). In the study from Wuhan, diabetic patients had higher levels of neutrophils $(P=0.014)$, C-reactive protein $(P=0.008)$, procalcitonin $(P<0.01)$, and D-dimer $(P=0.033)$, and lower levels of lymphocytes $(P=0.032)$ and albumin $(P=0.035)(6)$. IL6 and D-dimer levels at admission were higher in patients with hyperglycemia than in those with normoglycemia $(P=0.001)$ and both correlated with admission blood glucose levels in a study from Naples, Italy (46). This was similar to our study where a strong correlation between IL6 and plasma glucose at admission was observed.

\section{Glucose and COVID-19 severity association}

In our data, patients with plasma glucose of $180 \mathrm{mg} / \mathrm{dL}$ or less had better survival. This further emphasizes the role of optimal glycemic control during this difficult time, when regular follow-up is not available (47). It can be advised that all patients with DM should take regular medication and maintain a proper monitoring system to keep blood glucose $<180 \mathrm{mg} / \mathrm{dL}$ at all times as advised by various guidelines. In the CORONADO study from France, chronic microvascular and macrovascular complications of diabetes were significantly associated with increased risk of mortality in patients with COVID-19 (48). Elevated inflammatory markers such as D-dimer, ferritin and IL6 may also contribute to an increased risk of chronic diabetic complications in patients with pre-existing DM (49). Presence and progression of diabetic complications were not systematically evaluated in our study.

There are concerns that SARS-CoV-2, just like the SARS, could bind to ACE2 expressed on the pancreatic islets, leading to islet destruction and acute diabetes (50, 51). ACE2, which was previously thought to be restricted to the lungs, is expressed in many human tissues including the intestines, kidneys, myocardium, vasculature and pancreas islets besides the respiratory system $(52,53)$. The localization of ACE2 expression in the islets of pancreas along with hyperglycemia caused by SARS-CoV2 in people without pre-existing DM suggests that coronaviruses may specifically damage islets leading to hyperglycemia (50). Around $10 \%$ of patients in our group developed new-onset hyperglycemia. Tests for beta-cell function were not done in our study.

There were certain limitations in our study like we did not have HbA1c values for our patients which could have identified a subset of patients with new-onset hyperglycemia on admission having pre-existing diabetes. Nevertheless, it has been seen that acute hyperglycemia with or without diabetes is more predictive of mortality (2). Our study did not have results adjusted for obesity nor did its factors in diabetic complications or the use of drugs which could have led to hyperglycemia-like epinephrine. Steroid use was, however, not present in our cohort, based on the ICMR protocol for COVID-19 treatment at that time. Despite these limitations, this study does show conclusively that acute hyperglycemia was predictive of increased mortality in patients of COVID-19 and previously https://ec.bioscientifica.com https://doi.org/10.1530/EC-21-0086 (c) 2021 The authors Published by Bioscientifica Ltd
This work is licensed under a Creative Commons Attribution-NonCommercial-NoDerivatives 4.0 International License ifica com at $04 / 26 / 2023$ 12:08:01AM 
known diabetics had a three times higher mortality risk as compared to non-diabetics.

\section{Conclusions}

Random plasma glucose values on admission in patients hospitalized for COVID-19 is a strong predictor for disease severity and mortality. Increased age, longer duration of hospital stay, a requirement for oxygen including invasive ventilation, renal dysfunction, lymphopenia and elevated markers of inflammation were predictive of a higher mortality rate in patients of COVID-19. Although markers of inflammation were found to be elevated, the underlying mechanisms linking hyperglycemia and increased mortality need further research.

\section{Declaration of interest}

The authors declare that there is no conflict of interest that could be perceived as prejudicing the impartiality of the research reported.

\section{Funding}

This work did not receive any specific grant from any funding agency in the public, commercial, or not-for-profit sector.

\section{Acknowledgements}

The authors acknowledge the COVID-19 team of AlIMS Jodhpur, which made the necessary support system available for the care of patients. The authors are also thankful to all junior and senior resident doctors as well as nursing officers who were involved in patient care.

\section{References}

1 Chen N, Zhou M, Dong X, Qu J, Gong F, Han Y, Qiu Y, Wang J, Liu Y, Wei Y, et al. Epidemiological and clinical characteristics of 99 cases of 2019 novel coronavirus pneumonia in Wuhan, China: a descriptive study. Lancet 2020395 507-513. (https://doi.org/10.1016/S01406736(20)30211-7)

2 Grasselli G, Zangrillo A, Zanella A, Antonelli M, Cabrini L, Castelli A, Cereda D, Coluccello A, Foti G, Fumagalli R, et al. Baseline characteristics and outcomes of 1591 patients infected with SARSCoV-2 admitted to ICUs of the Lombardy region, Italy. JAMA 2020323 1574-1581. (https://doi.org/10.1001/jama.2020.5394)

3 Goyal P, Choi JJ, Pinheiro LC, Schenck EJ, Chen R, Jabri A, Satlin MJ, Campion TR, Nahid M, Ringel JB, et al. Clinical characteristics of Covid-19 in New York City. New England Journal of Medicine 2020382 2372-2374. (https://doi.org/10.1056/NEJMc2010419)

4 Holman N, Knighton P, Kar P, O'Keefe J, Curley M, Weaver A, Barron E, Bakhai C, Khunti K, Wareham NJ, et al. Risk factors for COVID19-related mortality in people with type 1 and type 2 diabetes in England: a population-based cohort study. Lancet: Diabetes and Endocrinology 20208 823-833. (https://doi.org/10.1016/S22138587(20)30271-0)

5 Wu C, Chen X, Cai Y, Xia J, Zhou X, Xu S, Huang H, Zhang L, Zhou X, Du C, et al. Risk factors associated with acute respiratory distress syndrome and death in patients with coronavirus disease 2019 pneumonia in Wuhan, China. JAMA Internal Medicine 2020180 934-943. (https://doi.org/10.1001/jamainternmed.2020.0994) 6 Shang J, Wang Q, Zhang H, Wang X, Wan J, Yan Y, Gao Y, Cheng J, Li Z \& Lin J. The relationship between diabetes mellitus and COVID-19 prognosis: a retrospective cohort study in Wuhan, China. American Journal of Medicine 2021134 e6-e14. (https://doi.org/10.1016/j. amjmed.2020.05.033)

7 Coppelli A, Giannarelli R, Aragona M, Penno G, Falcone M, Tiseo G, Ghiadoni L, Barbieri G, Monzani F, Virdis A, et al. Hyperglycemia at hospital admission is associated with severity of the prognosis in patients hospitalized for COVID-19: the Pisa COVID-19 study. Diabetes Care 202043 2345-2348. (https://doi.org/10.2337/dc20-1380)

8 Fadini GP, Morieri ML, Boscari F, Fioretto P, Maran A, Busetto L, Bonora BM, Selmin E, Arcidiacono G, Pinelli S, et al. Newlydiagnosed diabetes and admission hyperglycemia predict COVID-19 severity by aggravating respiratory deterioration. Diabetes Research and Clinical Practice 2020168 108374. (https://doi.org/10.1016/j. diabres.2020.108374)

9 Brealey D \& Singer M. Hyperglycemia in critical illness: a review. Journal of Diabetes Science and Technology 20093 1250-1260. (https:// doi.org/10.1177/193229680900300604)

10 Mechanick JI. Metabolic mechanisms of stress hyperglycemia. Journal of Parenteral and Enteral Nutrition 200630 157-163. (https://doi.org/10. 1177/0148607106030002157)

11 Turina M, Miller FN, Tucker CF \& Polk HC. Short-term hyperglycemia in surgical patients and a study of related cellular mechanisms. Annals of Surgery 2006243 845-851; discussion 851. (https://doi. org/10.1097/01.sla.0000220041.68156.67)

12 Bar-Or D, Rael LT, Madayag RM, Banton KL, Tanner AI, Acuna DL, Lieser MJ, Marshall GT, Mains CW \& Brody E. Stress hyperglycemia in critically ill patients: insight Into possible molecular pathways. Frontiers in Medicine 20196 54. (https://doi.org/10.3389/ fmed.2019.00054)

13 Esposito K, Nappo F, Marfella R, Giugliano G, Giugliano F, Ciotola M, Quagliaro L, Ceriello A \& Giugliano D. Inflammatory cytokine concentrations are acutely increased by hyperglycemia in humans: role of oxidative stress. Circulation 2002106 2067-2072. (https://doi. org/10.1161/01.CIR.0000034509.14906.AE)

14 Umpierrez GE, Isaacs SD, Bazargan N, You X, Thaler LM \& Kitabchi AE. Hyperglycemia: an independent marker of in-hospital mortality in patients with undiagnosed diabetes. Journal of Clinical Endocrinology and Metabolism 200287 978-982. (https://doi.org/10.1210/ jcem.87.3.8341)

15 Sung J, Bochicchio GV, Joshi M, Bochicchio K, Tracy K \& Scalea TM. Admission hyperglycemia is predictive of outcome in critically ill trauma patients. Journal of Trauma 200559 80-83. (https://doi. org/10.1097/01.TA.0000171452.96585.84)

16 Srinivasan V, Spinella PC, Drott HR, Roth CL, Helfaer MA \& Nadkarni V. Association of timing, duration, and intensity of hyperglycemia with intensive care unit mortality in critically ill children. Pediatric Critical Care Medicine 20045 329-336. (https://doi. org/10.1097/01.PCC.0000128607.68261.7C)

17 Wang S, Ma P, Zhang S, Song S, Wang Z, Ma Y, Xu J, Wu F, Duan L, Yin Z, et al. Fasting blood glucose at admission is an independent predictor for 28-day mortality in patients with COVID-19 without previous diagnosis of diabetes: a multi-centre retrospective study. Diabetologia 202063 2102-2111. (https://doi.org/10.1007/s00125-02005209-1)

18 Sachdeva S, Desai R, Gupta U, Prakash A, Jain A \& Aggarwal A. Admission hyperglycemia in non-diabetics predicts mortality and disease severity in COVID-19: a pooled analysis and meta-summary of literature. SN Comprehensive Clinical Medicine 20202 2161-2166. (https://doi.org/10.1007/s42399-020-00575-8)

19 Mirani M, Favacchio G, Carrone F, Betella N, Biamonte E, Morenghi E, Mazziotti G \& Lania AG. Impact of comorbidities and glycemia at 
admission and dipeptidyl peptidase 4 inhibitors in patients with type 2 diabetes with COVID-19: a case series from an academic hospital in Lombardy, Italy. Diabetes Care 202043 3042-3049. (https://doi. org/10.2337/dc20-1340)

20 Chang MC, Hwang JM, Jeon JH, Kwak SG, Park D \& Moon JS. Fasting plasma glucose level independently predicts the mortality of patients with coronavirus disease 2019 infection: a multicenter, retrospective cohort study. Endocrinology and Metabolism 202035 595-601. (https:// doi.org/10.3803/EnM.2020.719)

21 Mazori AY, Bass IR, Chan L, Mathews KS, Altman DR, Saha A, Soh H, Wen HH, Bose S, Leven E, et al. Hyperglycemia is associated with increased mortality in critically ill patients with COVID19. Endocrine Practice 202127 95-100. (https://doi.org/10.1016/j. eprac.2020.12.015)

22 Wang W, Shen M, Tao Y, Fairley CK, Zhong Q, Li Z, Chen H, Ong JJ, Zhang D, Zhang K, et al. Elevated glucose level leads to rapid COVID-19 progression and high fatality. BMC Pulmonary Medicine 20212164. (https://doi.org/10.1186/s12890-021-01413-w)

23 Gupta Y, Goyal A, Kubihal S, Golla KK \& Tandon N. A guidance on diagnosis and management of hyperglycemia at COVID care facilities in India. Diabetes and Metabolic Syndrome 202115 407-413. (https:// doi.org/10.1016/j.dsx.2021.01.015)

24 Marfella R, Paolisso P, Sardu C, Bergamaschi L, D’Angelo EC, Barbieri M, Rizzo MR, Messina V, Maggi P, Coppola N, et al. Negative impact of hyperglycaemia on tocilizumab therapy in Covid-19 patients. Diabetes and Metabolism 202046 403-405. (https://doi. org/10.1016/j.diabet.2020.05.005)

25 Mithal A, Jevalikar G, Sharma R, Singh A, Farooqui KJ, Mahendru S, Krishnamurthy A, Dewan A \& Budhiraja S. High prevalence of diabetes and other comorbidities in hospitalized patients with COVID-19 in Delhi, India, and their association with outcomes. Diabetes and Metabolic Syndrome 202115 169-175. (https://doi.org/10.1016/j. dsx.2020.12.029)

26 Bode B, Garrett V, Messler J, McFarland R, Crowe J, Booth R \& Klonoff DC. Glycemic characteristics and clinical outcomes of COVID-19 patients hospitalized in the United States. Journal of Diabetes Science and Technology 202014 813-821. (https://doi. org/10.1177/1932296820924469)

27 Wallia A, Prince G, Touma E, El Muayed M \& Seley JJ. Caring for hospitalized patients with diabetes mellitus, hyperglycemia, and COVID-19: bridging the remaining knowledge gaps. Current Diabetes Reports 202020 77. (https://doi.org/10.1007/s11892-020-01366-0)

28 Pal R, Banerjee M, Yadav U \& Bhattacharjee S. Clinical profile and outcomes in COVID-19 patients with diabetic ketoacidosis: a systematic review of literature. Diabetes and Metabolic Syndrome 2020 14 1563-1569. (https://doi.org/10.1016/j.dsx.2020.08.015)

29 Ghosh A, Anjana RM, Shanthi Rani CS, Jeba Rani S, Gupta R, Jha A, Gupta V, Kuchay MS, Luthra A, Durrani S, et al. Glycemic parameters in patients with new-onset diabetes during COVID-19 pandemic are more severe than in patients with new-onset diabetes before the pandemic: NOD COVID India Study. Diabetes and Metabolic Syndrome 202115 215-220. (https://doi.org/10.1016/j.dsx.2020.12.033)

$30 \mathrm{Wu}$ L, Girgis CM \& Cheung NW. COVID-19 and diabetes: insulin requirements parallel illness severity in critically unwell patients. Clinical Endocrinology 202093 390-393. (https://doi.org/10.1111/ cen.14288)

31 Gianchandani R, Esfandiari NH, Ang L, Iyengar J, Knotts S, Choksi P \& Pop-Busui R. Managing hyperglycemia in the COVID-19 inflammatory storm. Diabetes 202069 2048-2053. (https://doi.org/10.2337/dbi200022)

32 Groop LC, Bonadonna RC, DelPrato S, Ratheiser K, Zyck K, Ferrannini E \& DeFronzo RA. Glucose and free fatty acid metabolism in non-insulin-dependent diabetes mellitus. Evidence for multiple sites of insulin resistance. Journal of Clinical Investigation $1989 \mathbf{8 4}$ 205-213. (https://doi.org/10.1172/JCI114142)
33 Dhatariya KK, Glaser NS, Codner E \& Umpierrez GE. Diabetic ketoacidosis. Nature Reviews: Disease Primers 20206 40. (https://doi. org/10.1038/s41572-020-0165-1)

34 Stentz FB, Umpierrez GE, Cuervo R \& Kitabchi AE. Proinflammatory cytokines, markers of cardiovascular risks, oxidative stress, and lipid peroxidation in patients with hyperglycemic crises. Diabetes 200453 2079-2086. (https://doi.org/10.2337/diabetes.53.8.2079)

35 Lazarus G, Audrey J, Wangsaputra VK, Tamara A \& Tahapary DL. High admission blood glucose independently predicts poor prognosis in COVID-19 patients: a systematic review and dose-response metaanalysis. Diabetes Research and Clinical Practice 2021171108561. (https://doi.org/10.1016/j.diabres.2020.108561)

36 Chatterjee P. Is India missing COVID-19 deaths? Lancet 2020396657. (https://doi.org/10.1016/S0140-6736(20)31857-2)

37 Jain VK, Iyengar K, Vaish A \& Vaishya R. Differential mortality in COVID-19 patients from India and western countries. Diabetes and Metabolic Syndrome 202014 1037-1041. (https://doi.org/10.1016/j. dsx.2020.06.067)

38 Verity R, Okell LC, Dorigatti I, Winskill P, Whittaker C, Imai N, Cuomo-Dannenburg G, Thompson H, Walker PGT, Fu H, et al. Estimates of the severity of coronavirus disease 2019: a model-based analysis. Lancet: Infectious Diseases 202020 669-677. (https://doi. org/10.1016/S1473-3099(20)30243-7)

39 Perez-Saez J, Lauer SA, Kaiser L, Regard S, Delaporte E, Guessous I, Stringhini S, Azman AS \& Serocov-POP Study Group Serologyinformed estimates of SARS-CoV-2 infection fatality risk in Geneva, Switzerland. Lancet: Infectious Diseases 202121 e69-e70. (https://doi. org/10.1016/S1473-3099(20)30584-3)

40 Salje H, Kiem CT, Lefrancq N, Courtejoie N, Bosetti P, Paireau J, Andronico A, Hozé N, Richet J, Dubost CL, et al. Estimating the burden of SARS-CoV-2 in France. Science 2020369 208-211. (https://doi. org/10.1126/science.abc3517)

41 Zhou W, Ye S, Wang W, Li S \& Hu Q. Clinical features of COVID-19 patients with diabetes and secondary hyperglycemia. Journal of Diabetes Research 20202020 3918723. (https://doi.org/10.1155/2020/3918723)

42 Iacobellis G, Penaherrera CA, Bermudez LE \& Mizrachi EB. Admission hyperglycemia and radiological findings of SARS-CoV2 in patients with and without diabetes. Diabetes Research and Clinical Practice 2020 164 108185. (https://doi.org/10.1016/j.diabres.2020.108185)

43 Saand AR, Flores M, Kewan T, Alqaisi S, Alwakeel M, Griffiths L, Wang X, Han X, Burton R, Al-Jaghbeer MJ, et al. Does inpatient hyperglycemia predict a worse outcome in COVID-19 intensive care unit patients? Journal of Diabetes 202113 253-260. (https://doi. org/10.1111/1753-0407.13137)

44 Cheng Y, Yue L, Wang Z, Zhang J \& Xiang G. Hyperglycemia associated with lymphopenia and disease severity of COVID-19 in type 2 diabetes mellitus. Journal of Diabetes and Its Complications 202135107809. (https://doi.org/10.1016/j.jdiacomp.2020.107809)

45 Liu S, Zhang Q, Wang W, Zhang M, Liu C, Xiao X, Liu Z, Hu W \& Jin P. Hyperglycemia is a strong predictor of poor prognosis in COVID-19. Diabetes Research and Clinical Practice 2020167 108338. (https://doi. org/10.1016/j.diabres.2020.108338)

46 Sardu C, D’Onofrio N, Balestrieri ML, Barbieri M, Rizzo MR, Messina V, Maggi P, Coppola N, Paolisso G \& Marfella R. Outcomes in patients with hyperglycemia affected by Covid-19: can we do more on glycemic control? Diabetes Care 202043 1408-1415. (https://doi.org/10.2337/ dc20-0723)

47 Zhou K, Al-Jaghbeer MJ \& Lansang MC. Hyperglycemia management in hospitalized patients with COVID-19. Cleveland Clinic Journal of Medicine 2020 [epub]. (https://doi.org/10.3949/ccjm.87a.ccc012)

48 Cariou B, Hadjadj S, Wargny M, Pichelin M, Al-Salameh A, Allix I, Amadou C, Arnault G, Baudoux F, Bauduceau B, et al. Phenotypic characteristics and prognosis of inpatients with COVID-19 and diabetes: the CORONADO study. Diabetologia 202063 1500-1515. (https://doi.org/10.1007/s00125-020-05180-x) https://ec.bioscientifica.com

https://doi.org/10.1530/EC-21-0086 (c) 2021 The authors Published by Bioscientifica Ltd
This work is licensed under a Creative Commons Attribution-NonCommercial-NoDerivatives 4.0 elnternationab dicense.ifica.com at 04/26/2023 12:08:01AM 
49 Cheema AK, Kaur P, Fadel A, Younes N, Zirie M \& Rizk NM. Integrated datasets of proteomic and metabolomic biomarkers to predict its impacts on comorbidities of type 2 diabetes mellitus. Diabetes, Metabolic Syndrome and Obesity: Targets and Therapy 202013 2409-2431. (https://doi.org/10.2147/DMSO.S244432)

50 Yang JK, Lin SS, Ji XJ \& Guo LM. Binding of SARS coronavirus to its receptor damages islets and causes acute diabetes. Acta Diabetologica 201047 193-199. (https://doi.org/10.1007/s00592009-0109-4)
51 Pal R \& Banerjee M. COVID-19 and the endocrine system: exploring the unexplored. Journal of Endocrinological Investigation 202043 1027-1031. (https://doi.org/10.1007/s40618-020-01276-8)

52 Wang L, Liang J \& Leung PS. The ACE2/Ang-(1-7)/mas axis regulates the development of pancreatic endocrine cells in mouse embryos. PLoS ONE 201510 e0128216. (https://doi.org/10.1371/journal.pone.0128216)

53 Hikmet F, Méar L, Edvinsson Å, Micke P, Uhlén M \& Lindskog C. The protein expression profile of ACE2 in human tissues. Molecular Systems Biology 202016 e9610. (https://doi.org/10.15252/msb.20209610)

Received in final form 13 April 2021

Accepted 6 May 2021

Accepted Manuscript published online 6 May 2021 (c) 2021 The authors Published by Bioscientifica Ltd
This work is licensed under a Creative Commons Attribution-NonCommercial-NoDerivatives 4.0 enternationad dicense ifica. com at 04/26/2023 12:08:01AM 